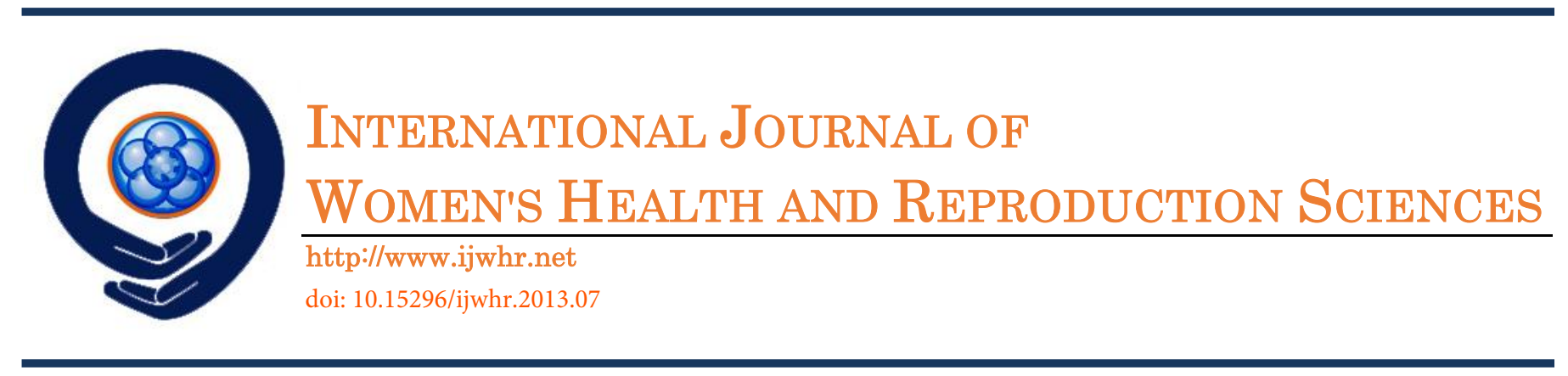

\title{
The Relationship Between Sexual Satisfaction and Education Levels in Women
}

\author{
Mehdi Abdoly ${ }^{1 *}$, L. Pourmousavi ${ }^{2}$
}

\section{Article History:}

Received April 2013

Accepted May 2013

Available online July 2013

\section{Keywords:}

Sexual Satisfaction

Education Level

Women

\section{Corresponding Author:}

Psychiatrist. Psychiatry department of Jahrom Medical Sciences University

Tel: +989143166809

Email: abdoly_m@yahoo.com

\begin{abstract}
Objective: Mental health professionals believe sexual satisfaction is one of the most important factors affecting women wellbeing and quality of life. Family consistency and marriage durability are dominantly dependent upon sexual life satisfaction. Different factors may affect sexual interest. To investigate significant relationship between sexual satisfaction and educational levels in women.

Material and Methods: subjects were 270 married women in the age range of 18-45 years old. Sexual satisfaction, sexual function indexes and demographic data have evaluated by formal known questioners: Sexual Satisfaction Scale for women (SSS-W) and Female Sexual Function Index (FSFI).

Result: There was not a lineal relation between sexual satisfaction and formal education level in participant women. Under diploma and doctorate education groups have had more sexual dysfunction and lower sexual satisfaction in comparison to other groups $(\mathrm{P}<0.001)$.

Conclusion: Higher formal education level necessarily does not bring better sexual function or sexual life satisfaction..
\end{abstract}

1. Psychiatrist. Psychiatry department of Jahrom Medical Sciences University

2. Nursing Master Degree. Jahrom Medical Sciences University 


\section{Introduction:}

Sexual wellbeing doesn't mean lack of sexual dysfunction necessarily. Sexual satisfaction almost refers to pleasant feeling of sexual activity or positive one's attitude to sexual behavior (1). Mental health professionals believe sexual satisfaction is one of the most important factors that affect women wellbeing and quality of life. Family consistency and marriage durability are dominantly dependent upon sexual life satisfaction. Some studies have reported nearly $70 \%$ of Tehranian women applying for divorce complain from sexual dissatisfaction in their sexual life. Interestingly, compliant from sexual dissatisfaction in women has been more than men (2). However, in most developing and traditional societies sexual concepts, especially sexual pleasure, are taboo. We observed this cultural beliefs against sexual pleasure demand dominantly in women in comparison with men. According to Patriarchal culture, in these traditional societies all kinds of pleasures devote to men, but women don't have any role except caring role of children or just bedfellow for men and nothing else. In this lexicon, woman should care man and his demands such as sexual demands. She would be satisfied if be a good partner for his man, but her own desire or pleasure is not important. Most studies have recently focused on couple sexual satisfactions unlike former beliefs. Some women believe that sexual concepts are slight and away from their high level. They believe only low social groups occupy their mind in sex, but academic graduation or brilliant social condition are more interesting for them in the way of competition with men. Strikingly little public health research has examined effective factors associated with sexual wellbeing. Some studies have focused on factors like age (3), frequency of sexual activity and orgasm (4-6); relationship status, stability, and intimacy (7-9); more permissive sexual attitudes (10); psychological wellbeing, depressive symptoms $(7,8,11)$ and sexual function or dysfunction(7).Additional factors studied among women include sexual guilt $(12,13)$ and goal setting (14). The purposes of our study were twofold: First, we wanted to assess the prevalence and correlates of sexual satisfaction among some of participant women in this study. Second, we wanted to explore how higher this satisfaction would be with education. Women with academic educations were compared to adult women with lower level of academic education, in their sexual satisfaction profiles and correlates.

\section{Material and Methods:}

This was a cross sectional study that has done in two different cities in two time frames (2011 and 2013) (Tabriz and Jahrom). Participants were 270 married women with the age range of 18-45 years. They have invited to take part in our study by social Medias or their some friends and some of them were medical students or nursing stuff in our study center. All of participants asked about sexual life quality by enveloped questionnaire .They were directed to complete questionnaires assessing demographic information, sexual satisfaction and sexual function.

\section{Measurement Tools:}

Sexual satisfaction: The Sexual Satisfaction Scale for Women (SSS-W) is a 30-item questionnaire that asks participants to rate their level of agreement with a series of statements on a 5-point Likert scale (17) . Scores range from 0 to 130 , with higher scores indicating greater levels of satisfaction. The SSS-W assesses five separate domains of sexual satisfaction supported by factors analysis, including ease and comfort discussing sexual and emotional issues; compatibility between partners in terms of sexual beliefs, preferences, desires, attraction, contentment with emotional and sexual 
aspects of the relationship; personal distress concerning sexual problems; and distress regarding the impact of their sexual problems on their partner and relationship.

Sexual Functioning: The Female Sexual Functioning Index (FSFI) is a 19-item questionnaire that is subdivided into six domains supported by factors analysis, including desire, arousal, lubrication, orgasm, satisfaction, and pain. The satisfaction domain was excluded for the calculation of the FSFI total score because of the overlap in the measurement of the sexual satisfaction construct as indicated by its high correlation with the SSS-W total in the current study

Like the same previous studies (18).

$\mathrm{K} 2$, fisher exact test, independent $\mathrm{T}$ test and Pearson correlation coefficient methods were used to analyze the data. $\mathrm{P}<0.05$ was considered significant. All data were analyzed by SPSS statistical software release 17.

\section{Results:}

Demographic characteristics of participants include 270 married women 18-45 years old age $(M=24.2, \quad S D=4.4)$. Their educational levels have been shown in figure 1.

We computed Pearson correlation to assess relationships between sexual satisfaction, sexual functioning and education level in participants. Sexual function was strongly correlated with sexual satisfaction $(r=0.6$, $\mathrm{P}<0.001)$. According to evaluations of SSSW total score and FSFI subscales, all of the sexual functioning domain scores were associated with sexual satisfaction.

By evaluation of SSS-w scores in participants, we have not seen a lineal correlation between education degree level and sexual satisfaction level. Under diploma education group and above master degree group had low sexual satisfaction score. Figure 2 demonstrates SSS-w score in each group.

In our study $70 \%$ of participants had dysfunction at least in one criterion of sexual function. The most reported dysfunction was low sexual desire (61\%) and the least was sexual pain (16.7\%). Sexual function scores had not lineal correlation with education degree level.
Under diploma and above master degree (dominantly doctorate and post doctorate) have had lower score in FSFI.

\section{Discussion:}

This study examined the association between different education levels and sexual satisfaction among some Iranian women. It was predicted that higher academic education level would be related to higher sexual satisfaction. Despite consistent with most previous studies, education level correlation with sexual satisfaction was lineal only for under doctorate level whereas surprisingly in doctorate and post doctorate level group, women had shown decline in sexual satisfaction scales. We suppose this lower sexual satisfaction might be caused by some factors, including higher education load pressure on daily activity, increasing age; stressful conditions for higher education degrees iterance for students, more trying in girls to access higher degrees in colleges and finally changes in women's attitude. They almost believe higher academic education degree would be most important advantage for them and they do not have need to their sexual attraction. Some studies have been stressed on the relationship of education level with marital satisfaction (19). The majority of present studies belong to developed and nontraditional societies, so we have few data about traditional or transiting from tradition to modern societies like Iranian society. Some limited data indicate that we encounter high degree of sexual dysfunction and consequently sexual dissatisfaction in Iranian women (15). Some vernacular studies figured out some factors like mental health profile, sexual activity before marriage, gynecological pathology, personality characteristics and lack of extra-marital relations (16).

In most health fields, higher socioeducational state is associated with more 
satisfactory well-being condition. We wanted to evaluate education degree role in sexual satisfaction in married women in our investigation. Our finding is in concordance with some recent studies in Iranian women society (19). Peleg-Sagy and Shahar reported high rate of depression and sexual dissatisfaction in female medical students (20). It seems this hypothesis (lineal correlation between education and sexual satisfaction levels) is rejected because not only the higher level of education does not indicate a higher level of cultural adjustment factor to be considered in the marital relationship but also sometimes individuals with higher education level have higher selfishness that it is a harmful factor in sexual relation. On the other hand, women with higher education level in Iranian educational system necessarily don't have higher sexual information or better attitude to sexual life. Lack of safe sexual information sources in Iran education systems or media and monopolized studies on formal literature make them poor in sexual knowledge.

\section{Conclusion :}

In spite of growing formal education level in Iranian female population, improving in their sexual life well-being and consequently their marital life consistency have failed due to lack of appropriate sexual education in every step of life. Growing data indicate higher divorce rate in higher educated women. Nonetheless, health care organization in Iran doesn't have any identified policy for this subject, So documented policy in sexual health care and specially improvement in women sexual knowledge are our society critical needs.

\section{Conflict of interest statement:}

We declare that we have no conflict of interest.

\section{Acknowledgments:}

We have no acknowledgements to disclose.
Figure 1: education levels in female participants

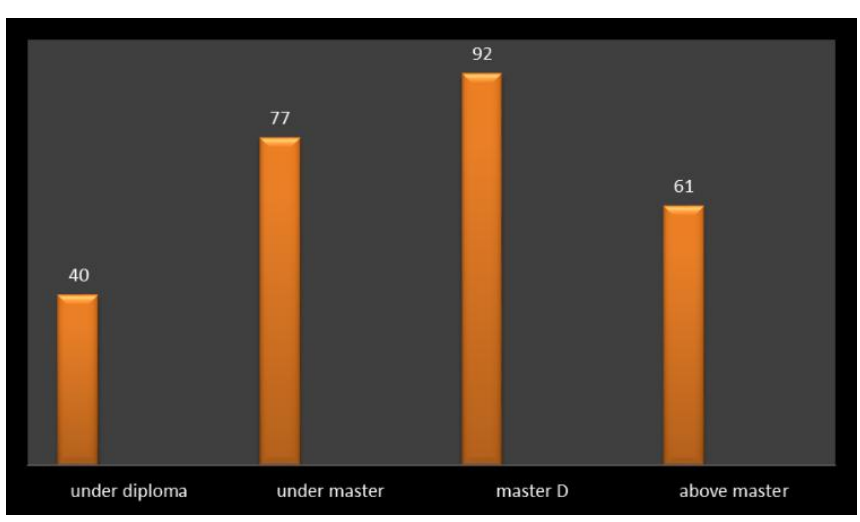

Figure 2: comparison of SSS-W score in different education level groups

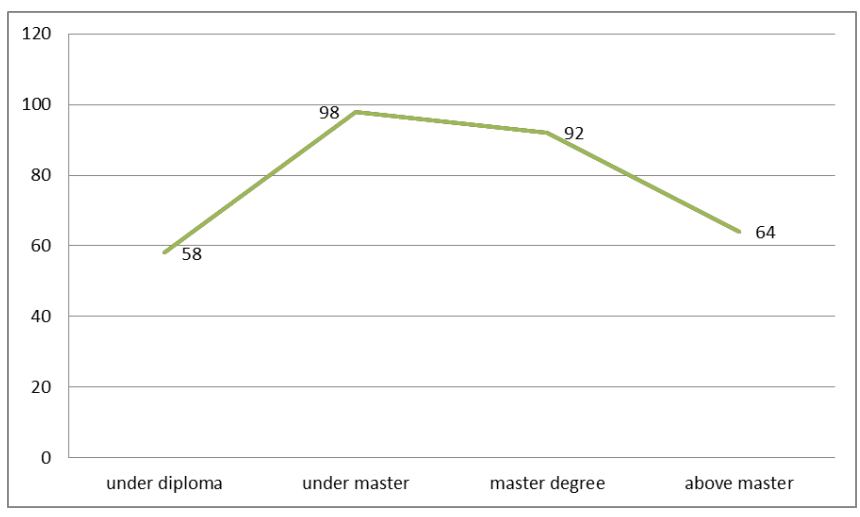




\section{References:}

1. Oriel J. Sexual pleasure as a human right: harmful or helpful to women in the context of HIV/AIDS? Womens Stud Int Forum. 2005; 28(5):392-404.

2. Aliakbari Dehkordi M. Relationship between woman sexual function and martial adjustment. J Behav Sci 2010; 4(3):199 -206. Persian.

3. Carpenter LM, Nathanson CA, Kim YJ. Physical women, emotional men: gender and sexual satisfaction in midlife. Arch Sex Behav. 2009; 38(1):87-107.

4. Young M, Denny G, Luquis R, Young T. Correlates of sexual satisfaction in marriage. Can J Hum Sex. 1998; 7(2): 115-127.

5. Haavio-Mannila E, Kontula O. Correlates of increased sexual satisfaction. Arch Sex Behav. 1997; 26(4): 399-419.

6. Young M, Denny G, Young T, Luquis R. Sexual satisfaction among married women age 50 and older. Psychol Rep. 2000; 86(3):1107-1122.

7. Dundon CM, Rellini AH. More than sexual function: predictors of sexual satisfaction in a sample of women age 40---70. J Sex Med. 2010; 7(2):896-904.

8. Henderson AW, Lehavot K, Simoni JM. Ecological models of sexual satisfaction among lesbian/bisexual and heterosexual women. Arch Sex Behav. 2009; 38(1):50-65.

9. Warehime MN, Bass LE. Breaking singles up: sexual satisfaction among women and men. Int J Sex Health. 2008; 20(4):247-261.

10. Haavio-Mannila E, Kontula O. Correlates of increase sexual satisfaction. Arch Sex Behav. 1997; 26(4): 399-419.

11. Bancroft J, Loftus J, Long JS. Distress about sex: a national survey of women in heterosexual relationships. Arch Sex Behav. 2003; 32(3):193-208

12. Moore NB, Davidson JK Sr. Guilt about first intercourse: an antecedent of sexual dissatisfaction among college women. J Sex Marital Ther. 1997; 23(1): 29-46.

13. Davidson JK Sr, Moore NB. Guilt and lack of orgasm during sexual intercourse: myth versus reality among college women. J Sex Educ Ther. 1994; 20(3):153-174.

14. Moore NB, Davidson JK Sr. College women and personal goals: cognitive dimensions that differentiate risk-reduction sexual decisions. J Youth Adolesc. 2006; 35(4):574-589.

15. Qavam M, Tasbihsazan R. Prevalence of married male \& female sexual dysfunction to family heaith clinic. Journal of urmia medical science. 2007; 18(4): 634-39. 
16. Ramezani M, Dolatian M, Shams J, Alavi H. The relationship between self-esteem and sexual dysfunction and satisfaction in women. AMUJ. 2012; 14(59): 57-65.

17. Meston C, Trapnell P. Development and validation of a five-factor sexual satisfaction and distress scale for women: The Sexual Satisfaction Scale for Women (SSS-W). J Sex Med 2005; 2(1): 66-81.

18. Rosen R, Brown C, Heiman J, Leiblum S, Meston CM, Shabsigh R, et al. The Female Sexual Function Index (FSFI): A multidimensional self-report instrument for the assessment of female sexual function. J Sex Marital Ther 2000; 26(2):191-208.

19. Bakhshayesh A.R, Mortazavi M. The relationship between sexual satisfaction, general health and marital satisfaction in couples. Journal of Applied Psychology . 2010; 3(4(12)): 73-85.

20. Peleg-Sagy T, Shahar G. The prospective associations between depression and sexual satisfaction among female medical students. J Sex Med. 2013; 10(7):1737-43. 